Journal of Bangladesh Academy of Sciences, Vol. 35, No. 1, 1-6, 2011

\title{
MERISTEM DEVELOPMENT AND ITS RELATION TO ENDOGENOUS GA 3 AND IAA CONTENTS DURING FLORAL BUD DIFFERENTIATION IN BROCCOLI
}

\author{
XINMEI JIANG, XIHONG YU ${ }^{1}$ AND DAN LI² \\ College of Horticulture, Northeast Agricultural University, Harbin-150030, China
}

\begin{abstract}
The effects of three temperature treatments on morphological changes in the apical meristem and contents of $\mathrm{GA}_{3}$ and IAA in leaves during floral bud differentiation in early maturing cultivar of broccoli were studied. Plants went through every stage of flower-bud differentiation at day/night temperatures of $17.3 \pm 1 / 9.3 \pm 1^{\circ} \mathrm{C}$. At $21.3 \pm 1 / 13.3 \pm 1^{\circ} \mathrm{C}$, floral bud development ceased after primary axillary scape primordium differentiation and apical meristem entered a reversion stage. The apical meristem remained in the vegetative growth phase in plants growing at $25.3 \pm 1 / 17.3 \pm 1^{\circ} \mathrm{C}$. Leaf $\mathrm{GA}_{3}$ contents started to increase while IAA contents started to decrease when plants entered the flower bud initiation stage. $\mathrm{GA}_{3}$ content was high and IAA content was low during all stages of axillary scape primordium differentiation.
\end{abstract}

Key words: Meristem development, Broccoli, Apical meristem, $\mathrm{GA}_{3}$, IAA

\section{INTRODUCTION}

Broccoli (Brassica oleracea L. var. italica) is commercially important vegetable in which commercial product is dependent on flower bud differentiation. There are three broccoli cultivars, namely early-maturing, mid-maturing, and late-maturing. In earlymaturing cultivars, early inflorescence development occurs if seedlings are transplanted in early spring when the temperature remains in the range from 10 to $17^{\circ} \mathrm{C}$. Therefore, research on flower bud differentiation in early-maturing broccoli is of great importance for commercial production. In this study, the effects of three temperature treatments on morphological changes in the apical meristem, and on $\mathrm{GA}_{3}$ and IAA contents in leaves were investigated in an early-maturing broccoli cultivar.

\section{MATERIALS AND METHODS}

The experiments were carried out at the Horticultural Experiment Station and the Plant Physiological-biology Laboratory of Agriculture, Northeast Agriculture University, Harbin, China.

Seeds of Brassica oleracea L. var. italica 'Qing-Feng Broccoli 103' were sown in a greenhouse on February 11, 2008. Seedlings with one or two leaves were transplanted

\footnotetext{
${ }^{1}$ Corresponding author: <yxh100@sohu.com>.

${ }^{2}$ Liaoyang Academy of Agricultural and Forestry Science, Liaoyang-111000, China.
} 
into culture pans. The seedlings were grown under a $25 \pm 0.5^{\circ} \mathrm{C} / 17 \pm 0.5^{\circ} \mathrm{C}$ day/night temperature regime with $540 \mu \mathrm{mol} / \mathrm{m}^{2} / \mathrm{s}$. illumination intensity during the day. On April 12, 2008, uniform seedlings with five leaves were placed in a growth cabinet with 72 $\mu \mathrm{mol} / \mathrm{m}^{2} / \mathrm{s}$. illumination intensity and 14 hours photoperiod for $30 \mathrm{~d}$. Three treatments differing in temperature were applied, viz. T1, T2 and T3 under day/night temperature of $17.3 / 9.3,21.3 / 13.3$ and $25.3 / 17.3^{\circ} \mathrm{C}$ ranged, respectively.

For each treatment there were three sets of replicates, and each set comprised of 30 plants. Flower bud differentiation in each treatment was assessed with an Olympus SZHILLD BO71 dissecting microscope. Plants were examined every three days from the day (0d) when the plants were placed in the growth cabinet. In addition, for scanning electron microscope observations, the apical meristem was fixed in a buffered $3 \%$ glutaraldehyde fixative (Karnovsky 1965), washed in Hanks solution and post-fixed in $1 \%$ osmium tetraoxide (Dalton 1955). After dehydration with graded propanol solutions the specimens were dried by the critical point method (Anderson 1951, Cohen et al. 1968) and then coated with coal and gold. Successive series of pictures of the apical meristems were produced by using a scanning electron microscope Hitachi S-570. Extraction, purification, and determination of $\mathrm{GA}_{3}$ and IAA were performed according to Luo et al. (1990). The leaves were taken every 3 days from the beginning when the plants were placed in the growth cabinet. Lyophilized leaves were grounded in liquid nitrogen and extracted with $60 \mathrm{ml}$ of $80 \%$ methanol/g of fresh weight. Extraction was carried out by stirring overnight at $4 \square$ in the dark and filtered to remove insoluble residues. The filtrate was reduced to an aqueous phase of $20 \mathrm{ml}$ in vacuum evaporator, alkalified with $0.2 \mathrm{M}$ $\mathrm{Na}_{2} \mathrm{HPO}_{4}$ to $\mathrm{pH} 8.0$ and extracted three times with an equal volume of acetidin/ligarine $(\mathrm{v} / \mathrm{v})$. The aqueous phases were acidified with $0.2 \mathrm{M}$ citric acid to $\mathrm{pH} 2.8$ and extracted three times with an equal volume of acetidin, then the organic phases were evaporated to dryness and the residue was dissolved in $5 \mathrm{ml}$ mixture of acetonitrile : methanol : $60 \%$ hawkinsin (5:50:45) and injected on to a HPLC (USA Water HPLC System) with a flow rate of $0.8 \mathrm{ml} / \mathrm{min}$.

\section{RESULTS AND DISCUSSION}

Morphological changes in the apical meristem before and after flower-bud differentiation: The morphological changes in the apical meristem mark the turning point when the plants switch to reproductive growth from vegetative growth. Flower-bud differentiation in broccoli requires exposure to a period of low temperature. Five developmental stages were distinguished in the apical meristem, namely vegetative growth, flower-bud initiation, primary, secondary and tertiary axillary scape primordium differentiation, and reversion stage (Table 1, Fig. 1). The apical meristem of plants in the $\mathrm{T} 3$ treatment remained in the vegetative growth phase throughout the experiment and did 
not exhibit any morphological change (Fig. 1, T3 $3_{-\mathrm{a}-1}, \mathrm{~T} 3_{-\mathrm{a}-2}$, and $\mathrm{T} 3_{-\mathrm{a}-3}$ ). The volume and surface area of the meristem were small. Some triangular phyllopodia were spirally differentiated surrounding the apical meristem.

Plants in the T2 treatment could undergo flower-bud differentiation, but could not complete the entire differentiation processes. Initiation of the flower-bud differentiation and the primary axillary scape primordium differentiation stages was a week later than in T1 plants. Thus the flower-bud initiation stage was initiated after 18 days (Fig. T2 the primary axillary scape primordium differentiation stage after 24 days in growth cabinet (Fig. 1 T2 ${ }_{-c}$ ). After this, the apical meristem stopped growing and entered into reversion stage, in which the volume and superficial area were greater than those of the apical meristem in the vegetative growth phase, and the apical meristem had the appearance of a steamed bun. This period was considered to be a stage of reversion of the apical meristem (Fig. 1 T2 ${ }_{- \text {e }}$ ).

Plants in the T1 treatment were passed through each stage of flower-bud differentiation. After incubation for 12 days, the plant entered the flower-bud initiation stage, with the apical meristem becoming gradually flattened and broader, its volume and surface area increased, and a protuberance was apparent inside the phyllopodia (Fig.1, $\mathrm{T} 1_{\text {-b }}$ ). After 18 days, the meristem entered the stage of primary axillary scape primordium differentiation; meanwhile, there were some protuberances all around the apical meristem (Fig.1, T1 $1_{-c}$ ). After 27 days plants entered the stage of secondary and tertiary axillary scape primordium differentiation.

Table 1. Effects of three temperature treatments on the stage of flower-bud differentiation in broccoli. Data are the number of days at each stage after broccoli plants were placed in a growth cabinet.

\begin{tabular}{cccc}
\hline \multirow{2}{*}{ Treatments } & \multicolumn{3}{c}{ Flower bud differentiation stage } \\
\cline { 2 - 4 } & $\begin{array}{c}\text { Flower bud } \\
\text { initiation }\end{array}$ & $\begin{array}{c}\text { Primary axillary scape } \\
\text { primordium differentiation }\end{array}$ & $\begin{array}{c}\text { Secondary and tertiary axillary } \\
\text { scape primordium differentiation }\end{array}$ \\
\hline T1 & 12 & 18 & 27 \\
T2 & 18 & 24 & - \\
T3 & - & - & - \\
\hline
\end{tabular}

The plant stopped flower-bud differentiation after entering the primary axillary scape primordium differentiation stage, and did not enter into the secondary and tertiary axillary scape primordium differentiation stage in the T2 treatment. Furthermore, the apical meristem remained similar in form to that at the flower-bud initiation stage (Fig. 1 T2 $2_{\text {e }}$ ). A possible reason for this was that, firstly, the accumulation of carbohydrate was inadequate during flower-bud differentiation. A lot of energy and nutrients are required during flower-bud differentiation, but in this study the broccoli palnts were treated in growth cabinet which illumination intensity was only $72 \mu \mathrm{mol} / \mathrm{m}^{2} / \mathrm{s}$. 
The authors think, respiration in the $\mathrm{T} 2$ treatment exceeded that in $\mathrm{T} 1$ while nutritional accumulation was lower than in $\mathrm{T} 1$. The primary axillary scape primordium had started to degrade because of inadequate nutrition.

Secondly, exposure to low temperature is required when the plants entered the flowerbud differentiation stage. According to Fujime and Okuda (Fujime et al. 1996), flower bud differentiation would stop, and even revert to the phyllopodium stage, if a high temperature of about $25^{\circ} \mathrm{C}$ was encountered after differentiation in cauliflower and broccoli. The results obtained during this study revealed that, if there was not enough low temperature, the plant could not finish all the stages of flower bud differentiation.

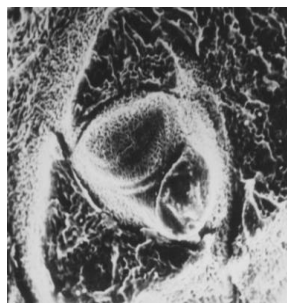

$\mathrm{T} 1_{-\mathrm{a}}$

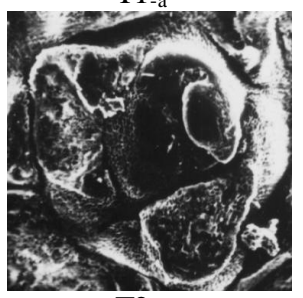

$\mathrm{T}_{2}$-a

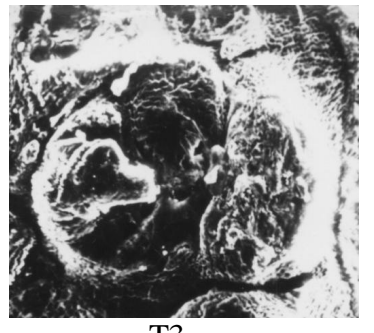

$\mathrm{T} 3_{-\mathrm{a}-1}$

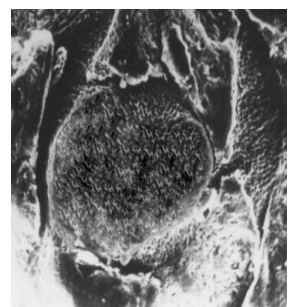

$\mathrm{T} 1_{-\mathrm{b}}$

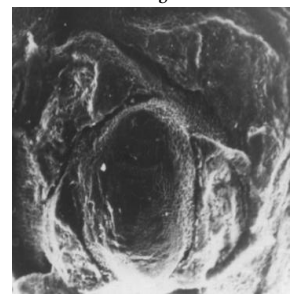

$\mathrm{T} 2$-b

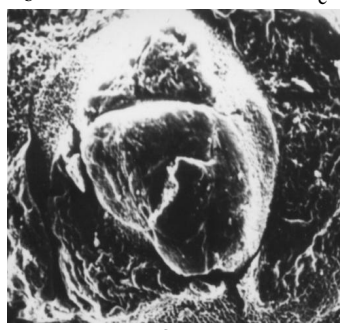

$\mathrm{T} 3_{-\mathrm{a}-2}$

$\mathrm{T} 1_{-\mathrm{c}}$

$\mathrm{T} 2_{-\mathrm{c}}$
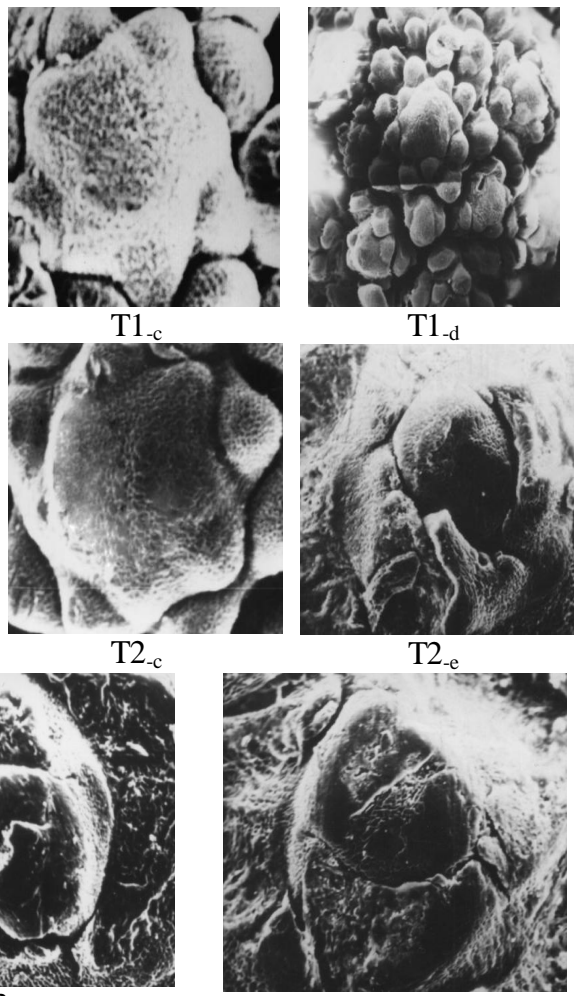

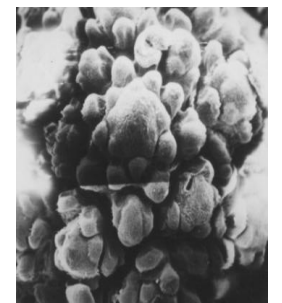

$\mathrm{T} 1_{-\mathrm{d}}$

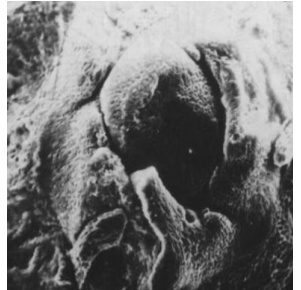

$\mathrm{T} 2$

$\mathrm{T} 3_{-\mathrm{a}-3}$

Fig. 1. Effects of three temperature treatments on the apical meristem in broccoli, a. vegetative growth $(\times 200)$, b. flower bud initiation $(\times 50)$, c. primary axillary scape primordium differentiation $(\times 150)$, d. secondary and tertiary axillary scape primordium differentiation $(\times 80)$, e. special stage of flower-bud differentiation (Reversion to vegetative growth) $(\times 120)$.

The $\mathrm{GA}_{3}$ and IAA contents exhibited little change when the apical meristem was in the vegetative growth phase (T3 treatment). Following exposure to low temperature in the $\mathrm{T} 1$ and $\mathrm{T} 2$ treatments, both the $\mathrm{GA}_{3}$ and IAA contents decreased gradually. $\mathrm{GA}_{3}$ contents decreased to minimum values at the flower bud initiation stage, whereas IAA 
contents continued to decrease after initiation of flowering, and subsequently the levels of both growth regulators increased. Each stage of inflorescence primordium differentiation was indicated to coincide with changes in the leaf $\mathrm{GA}_{3}$ and IAA contents. Gibberellins may have promoted the elongation and expansion of cells during growth. $\mathrm{GA}_{3}$ contents decreased when growth entered the flower-bud initiation stage. This finding is identical to those of Huang and Guan (1993) and Li et al. (2002), who investigated inflorescence differentiation in Brassica parachinensis. Maximum $\mathrm{GA}_{3}$ contents were recorded at the primary axillary scape primordium differentiation and secondary and tertiary axillary scape primordium differentiation stages, which agrees with our previous results (2004) on the stimulatory effects of low-temperature treatment of germinating seeds on flower-bud differentiation in broccoli. This indicated that each stage of axillary scape primordium differentiation needs a high $\mathrm{GA}_{3}$ content.

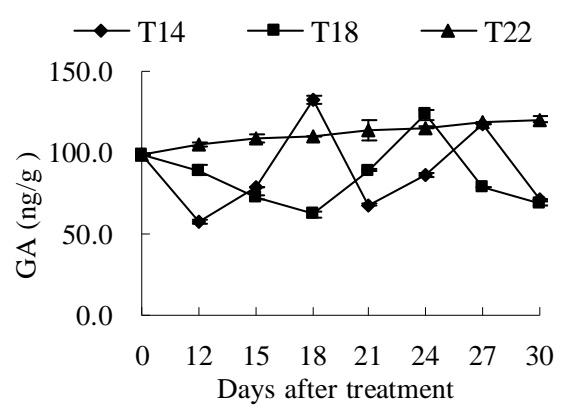

Fig. 2. Changes in $\mathrm{GA}_{3}$ content in leaves during flower-bud differentiation in broccoli under three temperature treatments

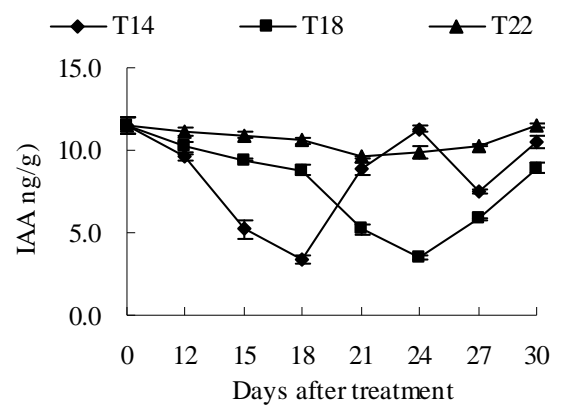

Fig. 3. Changes in IAA content in leaves during flower-bud differentiation in broccoli under three temperature treatments

The $\mathrm{GA}_{3}$ content was high whereas the IAA content was low during all stages of axillary scape primordium differentiation in broccoli. The lower the temperature, the shorter the time required for vernalization. Plants in lower temperature were able to go through each stage of flower-bud differentiation.

\section{ACKNOWLEDGMENTS}

This work was funded by the Innovative Team Project of Northeast Agricultural University (CXT002-2-2), and the Postgraduate's Innovative and Research Financing Project of Heilongjiang Province (YJSCX2008-092HLJ).

\section{REFERENCES}

Anderson, T.F. 1951. Techniques for preservation of three dimensional structure in preparing specimens for the electron microscope. New York Acad. Sci. Transactions Ser. II. 13:130-133.

Cohen, A.L., D.P. Marlow and G.Garner. 1968. A rapid critical point method using fluorocarbons (Freons) as intermediate and transitional fluids. J. de Microscopy. 7:331-342. 
Dalton, A.J. 1955. A chrome-osmium fixative for electron microscopy. Anatomical Record. 121:281.

Fujime, Y. and N. Okuda. 1996. The physiology of flowering in brassicas, especially about cauliflower and broccoli. Acta Horticul. 407: 247-254.

Huang, M.T. and P.C. Guan. 1993. Relationship between endogenous CTK and flowering stalk formation in Brassica parachinensis Bailey. South China Agric. Univ. 14(3): 87-91.

Jiang, X.M. and X.H Yu. 2004. Stimulatory effects of low temperature treatment of germinating seeds on flower-bud differentiation in broccoli. J. Plant Physiol. and Mol. Biol. 30(4):421-427.

Karnovsky, M.J. 1965. A formaldehyde glutaraldehyde fixative of high osmolarity for use in electron microscopy. J Cell Biol. 27:137-138.

Luo, Z.R., L.H. Zhu, M.C. Wu and W.C. Zhang. 1990. High performance liquid chromatography for GA3 content in plant tissue. Plant Physiology Communications. 26(2): 50-52.

Li, M.L., G.W. Zeng and Z.J. Zhu. 2002. Relationship of the levels of 5-methylcytosine in genomic DNA, gibberelllin and protein content with floral bud differentiation of Brassica parachinensis Barley. J. Zhejiang Agric. Univ. 28(2): 161-164.

(Received revised manuscript on 15 June, 2010) 